\title{
OBJETO E ESPAÇO: ANÁLISE DA PROPOSTA DE OSCAR NIEMEYER PARA O TEATRO MUNICIPAL DE UBERLÂNDIA
}

\author{
OBJETO Y ESPACIO. ANÁLISIS DE LA PROPUESTA DE OSCAR NIEMEYER PARA EL TEATRO \\ MUNICIPAL DE UBERLÂNDIA
} OBJECT AND SPACE: ANALYSIS OF THE OSCAR NIEMEYER'S PROPOSAL FOR THE MUNICIPAL
THEATER OF UBERLÂNDIA

\section{CARVALHO, LETÍCIA MARIA GONÇALVES}

Graduanda FAUeD, Universidade Federal de Uberlândia, leticia.investimentos.if@gmail.com

\section{BORDA, LUIS EDUARDO SANTOS}

Dr. Em Arquitetura, Docente FAUeD, Universidade Federal de Uberlândia, luiseduardoborda@yahoo.com.br

\section{RESUMO}

O presente trabalho é a tentativa de analisar as relações objeto/espaço presentes no projeto de Oscar Niemeyer para o Teatro Municipal de Uberlândia (Minas Gerais, Brasil). A ideia é questionar se, mais próximo ao debate contemporâneo, Niemeyer trata o entorno enquanto lugar; ou seja, se busca requalificar os arredores do teatro; ou se, mais próximo ao raciocínio moderno, trata os arredores como espaço abstrato. Para proceder a esta análise a investigação recorre à leitura da Carta de Atenas, a textos críticos sobre o debate contemporâneo (RIVAS SANZ, 1992; LAMAS, 1992; entre outros) e a abordagens sobre a obra de Oscar Niemeyer. A metodologia da pesquisa consiste em entender, primeiramente, as diferenças de abordagem em relação ao lugar: de um lado a perspectiva modernista de renovação total do espaço urbano, de outro lado o pensamento contextualista contemporâneo. Entendida a diferença entre tais abordagens, procede-se à análise da proposta de Niemeyer para o Teatro Municipal de Uberlândia

PALAVRAS-CHAVE: Oscar Niemeyer; teatro municipal de Uberlândia; espaço; lugar; arquitetura contemporânea; movimento moderno

\section{RESUMEN}

El presente trabajo es el intento de analizar las relaciones objeto / espacio presentes en el proyecto de Oscar Niemeyer para el Teatro Municipal de Uberlândia (Minas Gerais, Brazil). La idea es preguntarse si, más cerca del debate contemporáneo, Niemeyer trata el entorno como lugar; es decir, se busca recalificar los alrededores del teatro; o si, más cerca del raciocinio moderno, trata los alrededores como espacio abstracto. Para proceder a este análisis la investigación recurre a la lectura de la Carta de Atenas, a textos críticos sobre el debate contemporáneo (RIVAS SANZ, 1992; LAMAS, 1992; entre otros.) ya enfoques sobre la obra de Oscar Niemeyer. La metodología de la investigación consiste en entender, primero, las diferencias de abordaje en relación al lugar: por un lado la perspectiva modernista de renovación total del espacio urbano, por otro lado el pensamiento contextualista contemporáneo. Entendida la diferencia entre tales enfoques, se procede al análisis de la propuesta de Niemeyer Teatro Municipal de Uberlândia

PALABRAS CLAVES: Oscar Niemeyer; Teatro Municipal de Uberlândia; espacio; lugar; arquitectura contemporánea; Movimiento Moderno

\section{ABSTRACT}

The present work is the attempt to analyze the object / space relations present in the Oscar Niemeyer project for the Municipal Theater of Uberlândia (Minas Gerais, Brazil). The idea is to question whether, closer to the contemporary debate, Niemeyer treats the environment as a place; that is, if it seeks to requalify the surroundings of the theater; or if, closer to modern reasoning, it treats the surroundings as abstract space. In order to carry out this analysis, the research uses the reading of the Athens Charter, critical texts on the contemporary debate (RIVAS SANZ, 199; LAMAS, 1992; and others) and approaches to the work of Oscar Niemeyer. The research methodology consists in first understanding the differences of approach to the place: on the one hand the modernist perspective of total renovation of urban space, on the other side contemporary contextualist thinking. Given the difference between such approaches, the Niemeyer proposal is analyzed for the Municipal Theater of Uberlândia.

KEYWORDS: Oscar Niemeyer; Municipal Theater of Uberlândia; space; place; contemporary architecture; Modern Movement 


\section{INTRODUÇÃO: discussão sobre o espaço no Modernismo e na Contemporaneidade}

O Modernismo considerava a cidade tradicional como ambiente inadequado para a vida moderna e pretendia a renovação total do espaço da cidade; portanto, é natural que não tenha buscado estabelecer objetos arquitetônicos ajustáveis aos ambientes pré-construídos, mas sim construir estruturas que fundariam um novo espaço urbanístico. É natural, também, que, levado ao extremo, tal raciocínio tenha desembocado na ideia da "tabula rasa", concepção que considerava o espaço como "uma folha de papel em branco". Dentro disso, o arquiteto tentava colocar em prática a mentalidade moderna: organizacional, funcionalista e que pensava o espaço por setores (SANZ, 1992).

O espaço moderno baseia-se em medidas, posições e relações: é quantitativo, desdobra-se mediante geometrias tridimensionais, é abstrato, lógico, científico e matemático; é uma construção mental (MONTANER, 2001, p. 31 e 32).

Esta argumentação orientou a Carta de Atenas de 1933, que se configura como a construção material do pensamento racionalista e, a partir dele, tenta esquematizar os termos da atuação do arquiteto. Embora a Carta dispense um cuidado para com a topografia e para com as condições naturais dos sítios, ela defende a preservação do passado como um tipo de consentimento que se faz à história. Nela a avaliação das préexistências é altamente seletiva; analisa-se o bem monumental, por exemplo, como algo singular e, de certo modo, afastado do contexto urbano em que está inserido (MONTANER, 2001).

Um exemplo projetual dos princípios racionalistas encontrados na Carta de Atenas é a Ville Radieuse, proposta de Le Corbusier para a Paris de 1933. A proposta previa a renovação total do velho centro da cidade: ao invés do antigo traçado urbano, Le Corbusier propôs um traçado ortogonal e novos edifícios verticalizados, implantados num ambiente bastante arborizado, demonstrando uma preocupação estritamente funcionalista e organizacional.

Em contrapartida à cartilha modernista, a sensibilidade em relação ao sítio é um esforço recente, relacionado à arquitetura contemporânea, que se orienta pela ideia de lugar, propondo intervenções que revalorizem a história local, a memória coletiva e o estabelecimento de paisagens culturais significativas e singulares, e que promovam a vitalidade urbana dos locais de intervenção (ROSSI, 2001; MONTANER, 2001; LAMAS, 1992; ROWE, KOETTER, 1978; JACOBS, 2000).

Um autor contemporâneo que vai ressaltar a guinada contemporânea no que concerne ao modo de pensar as intervenções urbanísticas e arquitetônicas é o arquiteto italiano Aldo Rossi. Ele defende a ideia de que o ambiente urbano seja pensado não enquanto espaço abstrato (pensamento modernista) e sim enquanto "lugar". Ao associar o aspecto social ao meio construído, afirma que são os fatores culturais que determinam o espaço urbano e lhe conferem sentido. Nesse campo recorre ao conceito de "locus", como "aquela relação singular, mas universal, que existe entre certa situação local e as construções que se encontram naquele lugar" (ROSSI, 2001, p. 147).

Noções desse tipo estão ligadas à nossa cultura histórica, à nossa vida em paisagens construídas, às referências que fazemos em cada situação a outra situação; e, portanto, também ao encontro de pontos singulares, próximo de uma ideia do espaço tal como o havíamos imaginado (ROSSI, 2001, p. 149).

Estudiosos do espaço urbano como Jane Jacobs contribuem, no mesmo sentido, para o entendimento do espaço como uma organização complexa e criticam a ideia de cidade defendida pelo Movimento Moderno. Segundo a pesquisadora, os princípios urbanísticos modernos acarretam consequências desastrosas para o espaço urbano, pois promovem deterioração dos centros históricos, criação de ambientes áridos e inseguros, destruição da identidade local, massificação da maneira de habitar, entre outras (JACOBS, 2000).

A questão da vitalidade urbana é outra problemática discutida e desenvolvida por muitos críticos contemporâneos, os quais chamam a atenção para o caráter desolado de muitas propostas modernistas, desaprovam a existência de extensas áreas verdes e sem destinação precisa e defendem a necessidade de recuperar a vitalidade urbana que sempre foi típica da cidade tradicional (LAMAS, 1992; ROWE, KOETTER, 1978; JACOBS, 2000). Tais autores observam que, definidos para uma única função, os "setores" modernistas acabam sendo usados apenas nos períodos em que acontecem as atividades a eles destinadas. O resto do tempo mantém-se vazios. Assim, propõem que sejam buscadas soluções arquitetônicas e de planejamento urbano que recuperem a vida social nos ambientes da cidade.

Em Cidade Colagem, Rowe e Koetter (1978) já ressaltavam a importância da complexidade e da diversidade de atividades no espaço urbano. Enfatizavam, também, a importância de que os espaços contemporâneos buscassem resgatar a vitalidade típica da cidade tradicional. Opunham-se, deste modo, ao pensamento de fragmentação e setorização presente nas primeiras propostas modernistas. Os autores 
salientavam que "a arquitetura moderna havia invertido a proporção entre espaço livre e o espaço construído" e que as vastas áreas verdes afastavam as pessoas e geravam sensação de insegurança.

Famosa por suas críticas aos efeitos de muitas propostas modernistas, Jane Jacobs analisou grandes centros urbanos, concluindo que um ambiente saudável e vivo é um ambiente diverso, ou seja, um espaço que implica diversidade de usos e atividades combinadas, diferentes atores sociais e diferentes edificações. A investigadora observa que isso garante um maior número de usuários presentes no local e, consequentemente, sensação de segurança, definindo o que denomina "os olhos da rua". Em suas palavras: "nas cidades, a animação e a variedade atraem mais animação; a apatia e a monotonia repelem a vida" (JACOBS, 2000, p. 108).

O grau de acessibilidade urbana é outro fator que contribui para a fomentação da vitalidade urbana nos espaços públicos. A lógica é simples: quanto mais facilmente um espaço for acessado pelo sistema de mobilidade urbana, maior será o número pessoas que o frequentarão (SABOYA, 2017). Com base nesse entendimento, o autor destaca a importância de priorizar o investimento em transporte coletivo, diminuir o número de automóveis e entregar o espaço urbano ao pedestre.

Dentre todas essas opções (de locomoção), a mais ineficiente, sob diferentes pontos de vista, é o automóvel: sua capacidade de transporte é bastante limitada, seu gasto energético alto, o espaço que ocupa no sistema viário é proporcionalmente muito maior do que os outros modos de transporte e suas altas velocidades trazem riscos severos para os pedestres. Por isso, há uma clara tendência, já há algumas décadas, especialmente entre os estudiosos da cidade, no sentido de priorizar modos de transporte coletivos e não motorizados (SABOYA, 2017, s/p).

Outro aspecto que pode influir no grau de vitalidade urbana é o que Jane Jacobs (2000) denominou "fronteiras desertas" no espaço da cidade. É o caso, por exemplo, dos vastos espaços monofuncionais, dos grandes parques e dos extensos estacionamentos, espaços que eliminam a vitalidade social do ambiente urbano e geram sensação de insegurança.

Por sua vez, Kevin Lynch (2011) ressaltou a importância de garantir permeabilidade entre tais "fronteiras" e o espaço público. Assim como Jacobs, o autor reconhecia que as edificações que se comportam como barreiras (áreas extensas e exclusivas como campi universitários, grandes hospitais, etc.) são negativas para a vida social. Nesses casos, sugere que sejam pensadas soluções projetuais que possibilitem maior permeabilidade e evitem a perda da vitalidade e a quebra dos fluxos.

Enquanto a continuidade e a visibilidade são cruciais, os limites não devem ser impenetráveis. Muitos limites são uma costura de união, do que uma barreira isoladora. (LYNCH, 1980 p75)

Saneamento precário, insolação inadequada, ventilação insuficiente, poluição atmosférica e ruído causado pelos meios de transporte, entre outros, foram alguns dos problemas gerados pela Revolução Industrial. De acordo com Benévolo (1997), na tentativa de solucioná-los o Movimento Moderno utilizou uma visão sanitarista e racional, setorizou as diversas funções urbanas, propôs um espaço urbano mergulhado no verde, a verticalização das construções e a separação entre automóveis e pedestres, entre outras. Embora a meta fosse garantir tranquilidade, tal solução levou à perda da vitalidade que antes caracterizava o espaço das cidades.

Inserindo-se nesse contexto, o pensamento contemporâneo surgiu como uma revisão daquelas primeiras diretrizes modernistas. Percebeu-se, por exemplo, que, se a setorização resolvia alguns aspectos indesejados, ela gerava, por outro lado, espaços "desolados", sem vida urbana e que produziam sensação de insegurança. Foi a partir destas constatações e destas críticas que se passou a revalorizar a vitalidade dos espaços da cidade tradicional. Sem perder as boas contribuições do pensamento dos pioneiros, o pensamento contemporâneo busca agora um equilíbrio entre aquelas proposições e as considerações ponderadas pela crítica, ao que se somam as preocupações em preservar a memória coletiva e as identidades e especificidades locais (SANZ, 1992; ROSSI, 2001; BORDA, 2003).

\section{A ARQUITETURA E O URBANISMO DE OSCAR NIEMEYER: BREVE TRAJETÓRIA}

Nascido no Rio de Janeiro em 1907, o arquiteto e urbanista Oscar Niemeyer tem sido reconhecido pelos desafios estruturais e formais, sendo indiscutível sua filiação ao ideário da Arquitetura e do Urbanismo Modernos. Contribuiu para a afirmação deste ideário com o projeto do Ministério da Educação e da Saúde Pública (1936 - 1943). Juntamente com a equipe de arquitetos brasileiros, colocou em prática soluções 
modernas, como a sustentação por pilotis, a planta livre, o uso de quebra-sóis e demarcou, deste modo, o início de sua própria produção e a trajetória da arquitetura brasileira moderna (CASTILHO, 2008).

Com o conjunto da Pampulha, nos anos 40, o arquiteto começou a desenvolver uma linguagem autoral, muito embora procurasse corresponder à forte demanda por uma arquitetura "coletiva" e, sobretudo, "nacional". Em sua arquitetura ele introduziu as curvas e as formas livres, traços que acompanharam sua produção arquitetônica até seus últimos projetos (CASTILHO, 2008). Ao mesmo tempo que buscou soluções racionais e articuladas à lógica moderna, a partir dos anos 50 também investiu na expressividade de formas escultóricas, sólidas e concisas. Pode-se dizer, neste sentido, que, em suas mãos, o concreto significou muito mais do que um simples recurso estrutural; foi um modo de obter determinada forma plástica. Aliás, nesse campo Borda (2003) observa que, a partir dos anos 50, tornou-se quase senso comum considerar-se sua arquitetura como uma espécie de "escultura".

Lauro Cavalcante chama a atenção para o fato de que, a partir de 1957, fica nítido o nível de aprimoramento, leveza, simplificação e ousadia das formas em que passou a investir, enfatizando que arquitetura e estrutura são inseparáveis em prédios que parecem mal pousar no solo (CAVALCANTE, 2008). Além disso, a preocupação de Oscar Niemeyer era, também, destacar suas formas na paisagem urbana, o que, naturalmente, implicava em que contrastassem com o ambiente pré-construído (BORDA, 2003).

No que se refere a suas propostas urbanísticas, o que sempre buscou foi o sentido de integridade e unidade plástica. Para isso, buscou elaborar composições equilibradas, harmoniosas e geradas a partir de formas simples. De acordo com Borda (2003), seu objetivo sempre foi produzir belos conjuntos arquitetônicos, funcionais, e que proporcionassem uma leitura clara dos elementos colocados em jogo, no que utilizou parâmetros de ordenação plástica similares aos usados por Le Corbusier, como, por exemplo, o projeto para a reconstrução de Saint Dennis na França.

Para além desses aspectos plásticos, fica nítida, de qualquer modo, a adesão de Oscar Niemeyer a diversos princípios do Urbanismo Modernista. Veja-se, por exemplo, sua proposta para a Cidade Marina; assentamento projetado em 1957 para duzentos mil habitantes, seria construído nas proximidades de Brasília. Neste projeto ficam evidentes diversos princípios da proposta urbanística moderna: a divisão do espaço urbano por funções (setorização), a ideia da estrutura viária fluida e funcional, a separação do tráfego de pedestres do de automóveis, a criação de importantes espaços coletivos, entre outras diretrizes (PEREIRA, 1997; BORDA, 2003).

Questão fundamental e intrinsecamente vinculada à lógica de Niemeyer, a estrutura viária é uma das condições de viabilidade de seu ideal urbanístico. É o que garante o máximo de liberação de área verde, diminui significativamente os custos com infraestrutura e assegura fluxos automotivos rápidos (BORDA, 2014, p. 18).

Outro aspecto relevante para a análise de suas propostas urbanísticas é a criação de pontos coletivos de encontro. Entre vários exemplos, é possível perceber essa intenção no projeto urbanístico do Centro de Treinamento da Aeronáutica, em São José dos Campos (1947). Nesta proposta, Niemeyer propõe duas grandes praças pavimentadas e as articula a edifícios de interesse coletivo (BORDA, 2014).

No que se refere especificamente à criação de praças e espaços coletivos, alguns críticos consideram que, não obstante suas nobres intenções em prover espaços para a reunião e a expressão coletiva, Niemeyer frequentemente trai seus próprios objetivos ao gerar ambientes inóspitos (ZEIN, 1989). Borda (2003) ressalta que isso se dá por duas razões. A primeira delas deriva de sua preocupação em valorizar o aspecto impactante das formas, o que o leva a eliminar qualquer elemento ou vegetação que possa dificultar a apreensão geral da composição arquitetônica; o resultado são praças vazias e áridas, as quais só podem ser usadas à noite, quando o sol já se foi. A segunda razão é que, desprovidas de equipamentos que lhes deem apoio e, em geral, desconectadas do restante da vida urbana, tais praças e espaços só ganham vida nos horários em que as multidões as ocupam, ou quando são 'inventados' eventos que lhes deem significado e uso.

\section{TEATRO MUNICIPAL DE UBERLÂNDIA}

\section{História}

O processo burocrático e político implicado na construção do Teatro Municipal de Uberlândia arrastou a finalização da obra por mais de 30 anos. Segundo a jornalista Fernanda Torquato, a demora em concretizar o projeto foi "porque a cultura nunca foi prioridade para quem estava no poder ou para a maioria das pessoas em Uberlândia" (TORQUATO, 2016, p.10). 
Tudo começou em 1978 quando o então prefeito Virgílio Galassi pediu ao arquiteto Saul Vilela que projetasse um teatro, a ser construído na praça Sergio Pacheco. O mandato do prefeito terminou sem que, todavia, o projeto começasse a ser construído. A iniciativa foi retomada em 1989, quando Galassi assumiu seu terceiro mandato e solicitou um projeto ao arquiteto Oscar Niemeyer. O local seria, agora, o terreno onde hoje está a Reitoria do Campus Santa Mônica da Universidade Federal de Uberlândia (UFU). A obra, que a esta altura era nomeada como Centro Cultural, seria viabilizada com recursos de empresários da cidade e viabilizada a partir da Lei Sarney de incentivo à Cultura. O espaço seria composto por um teatro de arena, uma biblioteca e uma galeria de arte. Por várias razões, Galassi também não obteve sucesso nesta segunda tentativa.

A discussão sobre a construção só foi resgatada quando o prefeito voltou ao poder em 1998; ou seja, dez anos depois. Nesse momento, o projeto foi realocado na Avenida Rondon Pacheco e agora nomeado como Teatro Municipal de Uberlândia. As obras começaram em 1999, porém a construção se prolongou por anos. De acordo com a pesquisa de Torquado (2016), as justificativas para a demora da finalização da obra foram diversas: falta de verba, descrença da classe empresarial em fazer doações, diferentes interesses políticos, mudanças de governo e até mesmo a desconfiança da população em relação à necessidade de uma construção cultural de tal porte.

A obra prosseguiu de maneira mais acelerada em alguns momentos; em outros, o canteiro de obras ficou abandonado; questões administrativas precisavam ser solucionadas. Algumas paredes foram levantadas em 2003 e, até 2008, as obras seguiram instáveis. Este período correspondeu ao governo de Zaire Rezende e foi marcado por escassez de recursos. No governo seguinte viu-se uma iniciativa maior para que as obras do teatro fossem finalizadas. Era o governo de Odelmo Leão, prefeito que utilizou a Lei Rouanet, possibilitando, desta forma, que várias empresas contribuíssem para a finalização do teatro.

A arrancada nas obras foi impulsionada pela adesão de empresas como a Vale do Rio Doce, Usiminas e Fiat à Lei Rouanet, além de $R \$ 2$ milhões de reais do orçamento da prefeitura que tinha sido alocado para a obra (TORQUADO, 2016, p. 212)

De 2008 a 2012, portanto, a obra se desenvolveu rapidamente. Finalmente, em 20 de dezembro de 2012 o teatro foi inaugurado e entregue à população. Isso não significou, todavia, o funcionamento imediato do edifício; a falta de certos aparatos técnicos (iluminação, som, etc) impedia o pleno funcionamento do espaço. Foi quando artistas locais fizeram uma intervenção artística chamada "des-inauguração". O intuito era chamar atenção para o que consideravam um certo "descaso" do poder público para com o teatro (TORQUADO, 2016).

Atualmente, o teatro é o principal local de apresentações artísticas na cidade. Os eventos acontecem tanto no interior quanto no exterior do edifício, uma vez que o palco também se abre para a praça. Esta, por sua vez, muitas vezes funciona autonomamente e sedia diversos eventos.

\section{O edifício em relação à problemática do lugar}

A análise das relações entre o Teatro Municipal de Uberlândia e a cidade deixa claro que a construção, mesmo tendo sido concebida contemporaneamente, implica um raciocínio filiado às típicas intenções dos pioneiros da Arquitetura e do Urbanismo Modernos.

$\mathrm{Na}$ narrativa que Niemeyer faz do seu processo projetual, por exemplo, já ficam claras as questões que prioriza: preocupações com a estrutura do prédio, com a topografia e com a relações entre palco e plateia. Escreve o arquiteto:

A ideia que me ocorreu foi encontrar uma solução na qual o palco tivesse duas funções diferentes. Uma, servir ao teatro propriamente dito; outra aos espetáculos de música popular e rock. Isso evita, sejam em festivais, realizá-los dentro do teatro com público reduzido e prejuízo. Trata-se de solução nova que dará ao teatro de Uberlândia o sentido renovador que desejávamos. Provido de todos os requisitos que um teatro requer, o nosso projeto apresenta a economia indispensável, com a plateia apoiada no térreo e sem os problemas de estrutura usuais. E o terreno adaptado às curvas de nível que a visibilidade exige (NIEMEYER, 1989, s/p).

É também significativo observar, por outro lado, que, nos croquis que desenha, Niemeyer não inclui qualquer elemento pré-existente. É como se o espaço surgisse num descampado. É possível notar, por outro lado, que Niemeyer prioriza a relação do edifício com o contexto geral da cidade e não com o bairro em que se insere (Figura 6), ou seja, não dispensa atenção para com o entorno imediato ao edifício. Sua localização, próxima a vias de acesso rápido (Avenida Rondon Pacheco e Rodovia 050), bem como o amplo 
estacionamento, deixam claro que o que privilegia é o acesso por automóvel, não a relação pedestre/edifício e a acessibilidade por outros meios de transporte que não o carro (Figura 1 e Figura 2).

Figura 1: Mapa Esquemático do Teatro Municipal de Uberlândia, com legenda

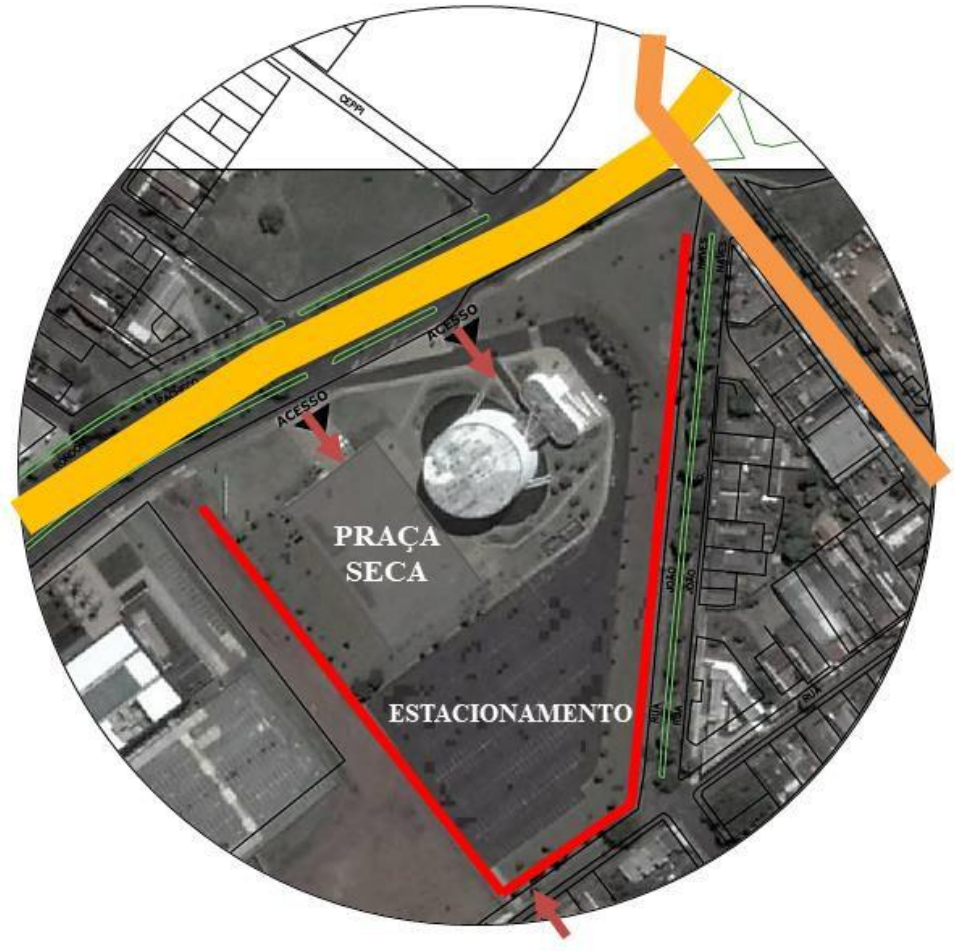

LEGENDA:

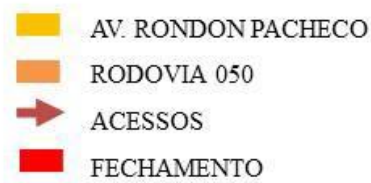

Fonte: Carvalho (2017)

Figura 2: Extensão do estacionamento do teatro

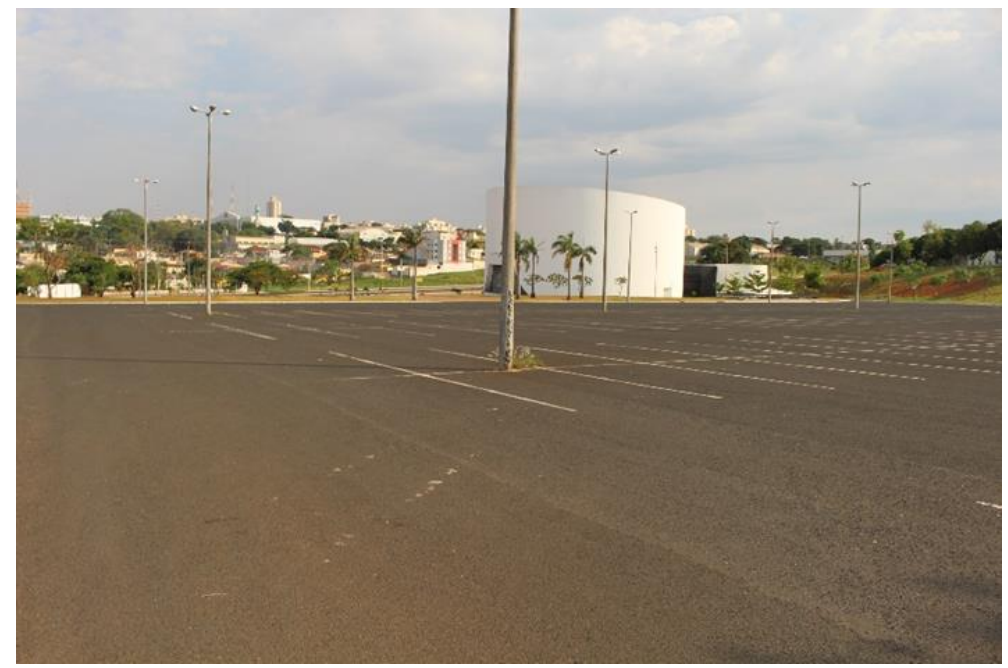

Fonte: Carvalho (2017)

Outro aspecto a destacar é que, se por um lado, o acesso por automóvel é favorecido, não há preocupação com a vitalidade urbana do local onde se insere o equipamento cultural. Isso se dá em função da não diversidade de atividades e usos, algo que propiciaria movimento, fluxo de pessoas em diferentes horários e, também, uma sensação de maior segurança aos usuários.

Também contribuem para a sensação de isolamento e aridez do espaço o extenso estacionamento e o fechamento em alambrado. O ambiente do teatro acaba configurando-se, deste modo, como uma zona de fronteira no meio urbano; torna-se uma barreira, eliminando a permeabilidade entre o bairro e a Avenida Rondon Pacheco. Em função do estacionamento, do acentuado declive de um dos lados e do alambrado, o 
edifício acaba se isolando do próprio bairro onde se insere. O resultado é certa sensação de vulnerabilidade e insegurança, ao invés do movimento e da vida urbana esperados para um equipamento público desse porte.

Outro fator que contribuiu para a sensação de aridez do espaço deriva da intenção de Niemeyer em destacar o objeto arquitetônico no contexto urbano. Eliminando vegetação ou qualquer elemento que pudesse impedir a livre apreciação da forma, Niemeyer acabou gerando um espaço inóspito para o uso diurno; isto é, não se preocupou em prover árvores ou áreas sombreadas que protegessem as pessoas do sol intenso. O resultado foi um ambiente desconfortável para as atividades diurnas (Figuras 4 e 5).

Somou-se a isso a inexistência de qualquer equipamento que pudesse contribuir para a vitalidade do espaço (café, comércio, serviços, equipamentos urbanos etc.). É certo que foi previsto um anexo (biblioteca, espaço expositivo, administração, etc.); porém, mesmo que construído, isso certamente não seria suficiente para dinamizar o espaço já que não foram pensadas estratégias projetuais efetivas de dinamização do ambiente construído e de sua articulação com o bairro.

Por todas essas razões aqui elencadas, a praça tornou-se um ponto de uso efetivo somente em momentos e usos muito pontuais; quase sempre, à noite. É o caso da Virada Cultural (Figura 3), evento de grande porte e que acontece na praça do Teatro uma vez ao ano; é o caso, também, de eventos vinculados a ocasiões comemorativas e a outras atividades culturais da cidade (Figura 3). No dia a dia, o espaço acabou sendo usado apenas para uso esportivo, como patinação e ciclismo (Figura 4); isso ocorre, aliás, principalmente no período noturno ou no começo da manhã, pois somente neste período é possível evitar o sol intenso que incide na praça. Ou seja: no dia a dia, o ambiente do Teatro e sua praça ressentem-se de usos, fluxos, atividades e movimento, algo que lhe conferiria a vitalidade urbana esperada para um equipamento cultural de tal importância (Figura. 5 e Figura 7).

Finalmente, diríamos que, se a monumentalidade, o caráter escultórico e a força imagética do edifício o transformaram num elemento icônico e marcante no contexto urbano, tem permanecido, no dia a dia, sem a vitalidade desejada e se mantido desconectado do restante da cidade.

Figura 3: Praça do Teatro Municipal de Uberlândia (evento noturno)

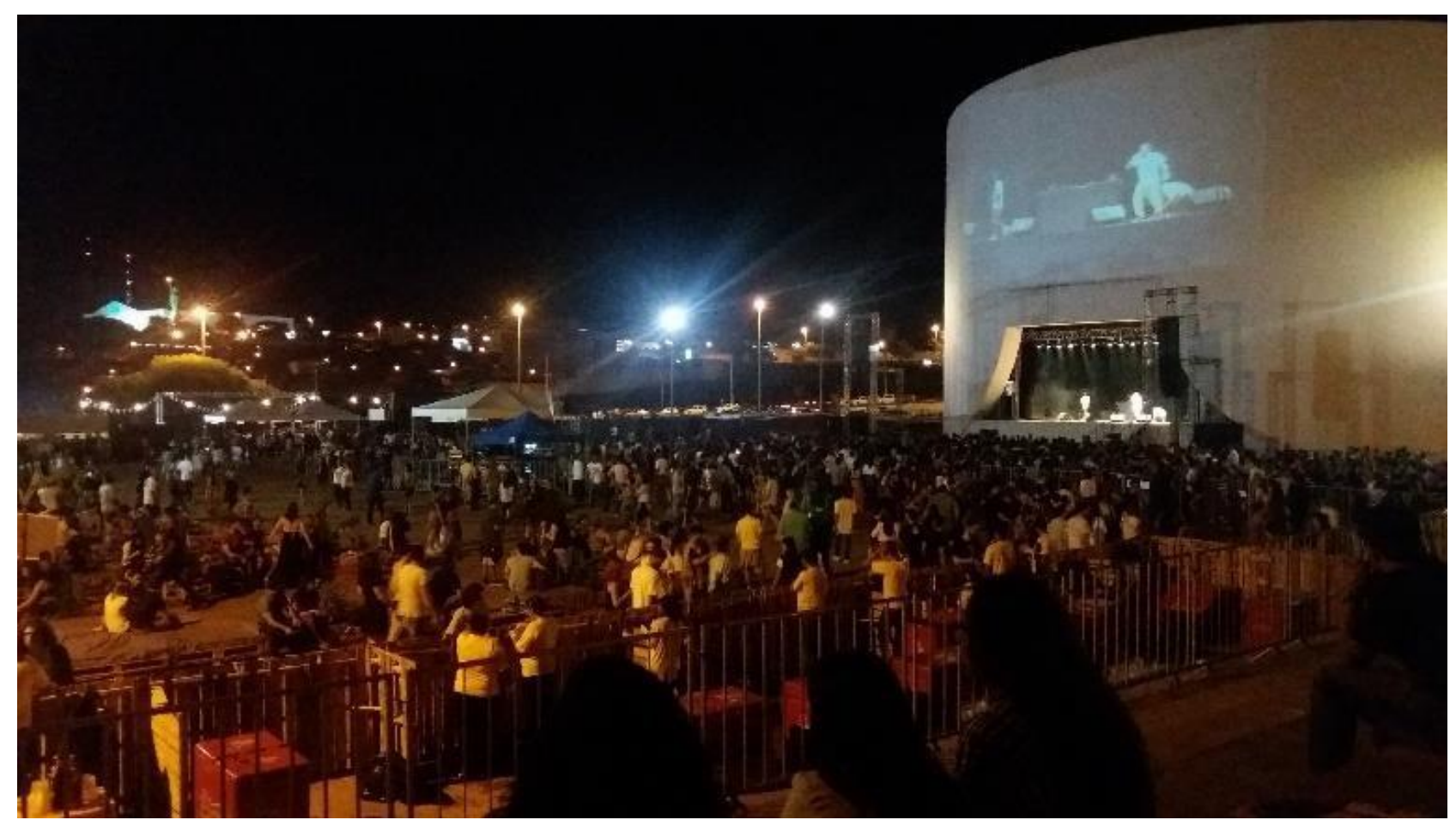

Fonte: Carvalho (2017) 
Figura 4: Praça do Teatro Municipal de Uberlândia

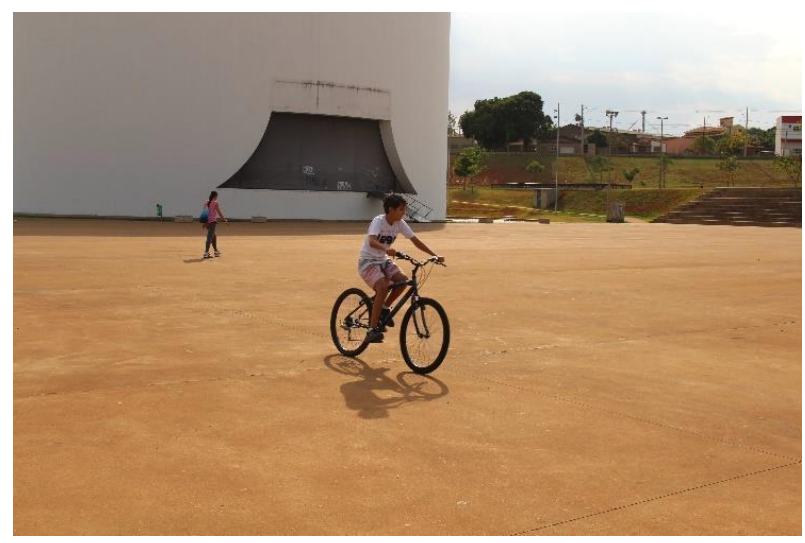

Figura 6: Entorno imediato

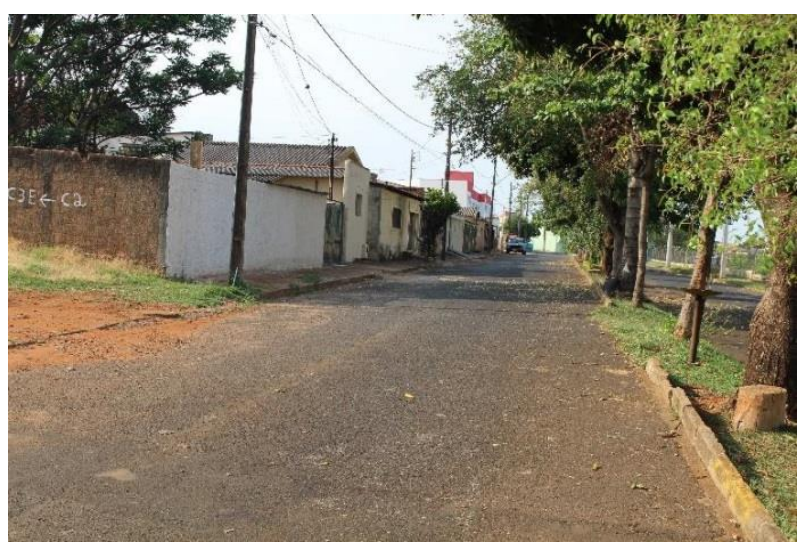

Figura 5: Teatro Municipal de Uberlândia

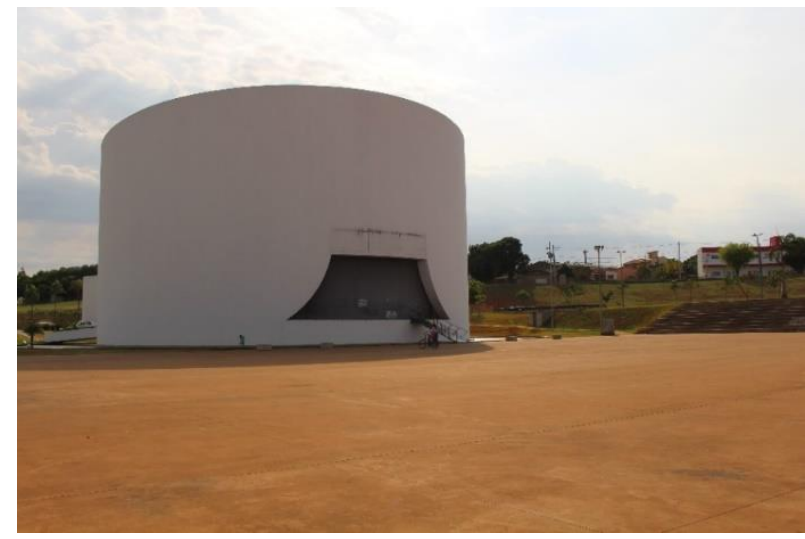

Figura 7: Apropriação do ambiente (criança escorrega na rampa)

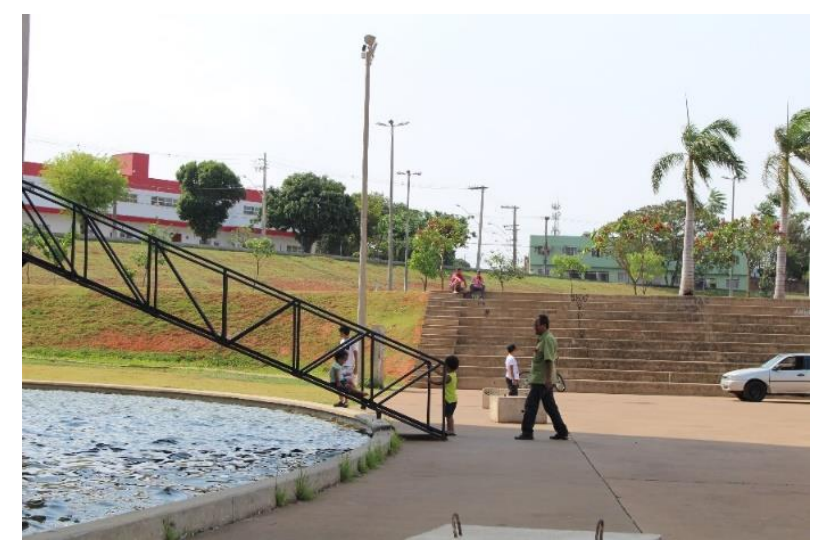

Fonte (Figuras 4 a 7): Carvalho (2017)

\section{CONSIDERAÇÕES FINAIS}

Se o Urbanismo Modernista considerava a cidade tradicional e as estruturas pré-existentes como inapropriadas para o ritmo da vida moderna, se optava pelo princípio da "tabula rasa" e via na renovação total do meio urbano uma oportunidade de criar um novo espaço urbano, o debate contemporâneo, por sua vez, passou a ver nas intervenções urbanas o oposto disso: uma oportunidade para resgatar uma série de qualidades da cidade tradicional, trazer de volta a vitalidade urbana perdida, garantir a integração das novas estruturas às formas pré-existentes e atuar de modo respeitoso em relação as passado e à memória coletiva (RIVAS SANZ, 1992; JACOBS, 2000, e outros).

No que tange especificamente à proposta do Teatro Municipal de Uberlândia, nota-se que Niemeyer preocupou-se quase que exclusivamente com as relações funcionais entre palco e plateia e em garantir o fácil acesso dos automóveis. O acesso dos veículos já estava assegurado, aliás, pela simples localização do edifício junto a vias de trânsito rápido. Deixou de considerar, por outro lado, não menos que duas questões contemporâneas: as conexões do edifício com o bairro e a possibilidade de pensar a proposta como uma oportunidade de produzir um lugar que implicasse movimento, vários usos e que, deste modo, garantisse a vitalidade esperada para um equipamento cultural de tal magnitude.

A proposta ficou longe, portanto, das preocupações contemporâneas. Ficou restrita, por outro lado, a questões mais limitadas. Mais próximo ao princípio modernista da setorização do espaço urbano, o edifício acabou configurando-se como um equipamento isolado, de uso estritamente cultural, facilmente acessível para o automóvel, porém desconectado do contexto e incapaz de promover a desejada vitalidade urbana. 


\section{REFERÊNCIAS}

BENEVOLO, L. O último capítulo da Arquitectura Moderna. Lisboa: Edições 70, 1997.

BORDA, L. E. O Nexo da Forma - Oscar Niemeyer: da Arte Moderna ao Debate Contemporâneo. Tese de Doutorado. Escola de Comunicação e Artes (ECA)/USP. São Paulo, 2003.

BORDA, L. E. Oscar Niemeyer e o Debate Urbanístico. Pesquisa de Pós-Doutorado. Programa de Pós-graduação em Arquitetura e Urbanismo. FAU/USP, São Paulo, 2014.

BRUAND, Y. Arquitetura Contemporânea no Brasil. 4. ed. São Paulo: Nova Perspectiva, 2008.

CAVALCANTE, L. Oscar Niemeyer: Trajetória e Produção Contemporânea 1936- 2008. Curitiba, 2008.

FUNDAÇÃO OSCAR NIEMEYER. Teatro Municipal de Uberlândia - Centro Cultural de Uberlândia. Disponível em: http://www.niemeyer.org.br/obra/pro307 Acessado em: 06 de agosto de 2017.

JACOBS, J. Morte e Vida das Grandes Cidades. São Paulo: Martins Fontes, 2000.

LAMAS, J. Morfologia Urbana e Desenho da Cidade. Lisboa: Fundação Calouste Gulbenkian, 1992.

LE CORBUSIER. A Carta de Atenas. São Paulo: HUCITEC/EDUSP, 1993.

LYNCH, Kevin. A imagem da cidade. São Paulo: Martins Fontes, 1980.

MONTANER, J. M. A Modernidade Superada: Arquitetura, Arte e o pensamento do século XX. Barcelona: Gustavo Gili, 2001.

PEREIRA, M. A. Arquitetura, texto e contexto: O discurso de Oscar Niemeyer. Brasília: Universidade de Brasília, 1997.

RIVAS SANZ, J. L. El Espacio como Lugar: Sobre la natureza de la forma urbana. Valladolid: Varona, 1992.

ROSSI, A. A Arquitetura da Cidade. 2. Ed. São Paulo: Martins Fontes, 2001.

ROWE, C.; KOETTER, F. Ciudad Collage. Barcelona: Editorial Gustavo Gili, S.A, 1978.

SABOYA, R.; NETTO, V. M.; VARGAS, J. C. Fatores morfológicos da vitalidade urbana: uma investigação sobre o tipo arquitetônico e seus efeitos. Arquitextos - Vitruvius, v. 180.02, 2015.

SANZ, J. L. R. El Espacio como Lugar: Sobre la Naturaleza de la Forma Urbana. Valladolid: Secretariado de Publicaciones, Universidad, D.L., 1992.

SILVA, F. T. B. Entre Retas e Curvas: realização de um documentário audiovisual sobre a história do Teatro Municipal de Uberlândia e seu papel na disseminação da cultura. Dissertação (Mestrado). Programa de Pós-Graduação em Tecnologias, Comunicação e Educação. Universidade Federal de Uberlândia, Uberlândia, 2016.

ZEIN, R. V. Descubra os Sete Erros. Revista Projeto, № 120. São Paulo: Arco Editorial Ltda, 1989.

NOTA DO EDITOR $\left(^{\star}\right)$ O conteúdo do artigo e as imagens nele publicadas são de responsabilidade do(s) autor(es). 